\title{
A Comparison of Imputation Strategies for Ordinal Missing Data on Likert Scale
}

\section{Variables}

\author{
Wei Wu and Fan Jia \\ University of Kansas \\ Craig Enders \\ Arizona State University
}

\section{Supplementary Material}

\section{Appendix A}

$\mathrm{R}$ code for the normal data model and logistic regression model approaches for the empirical example.

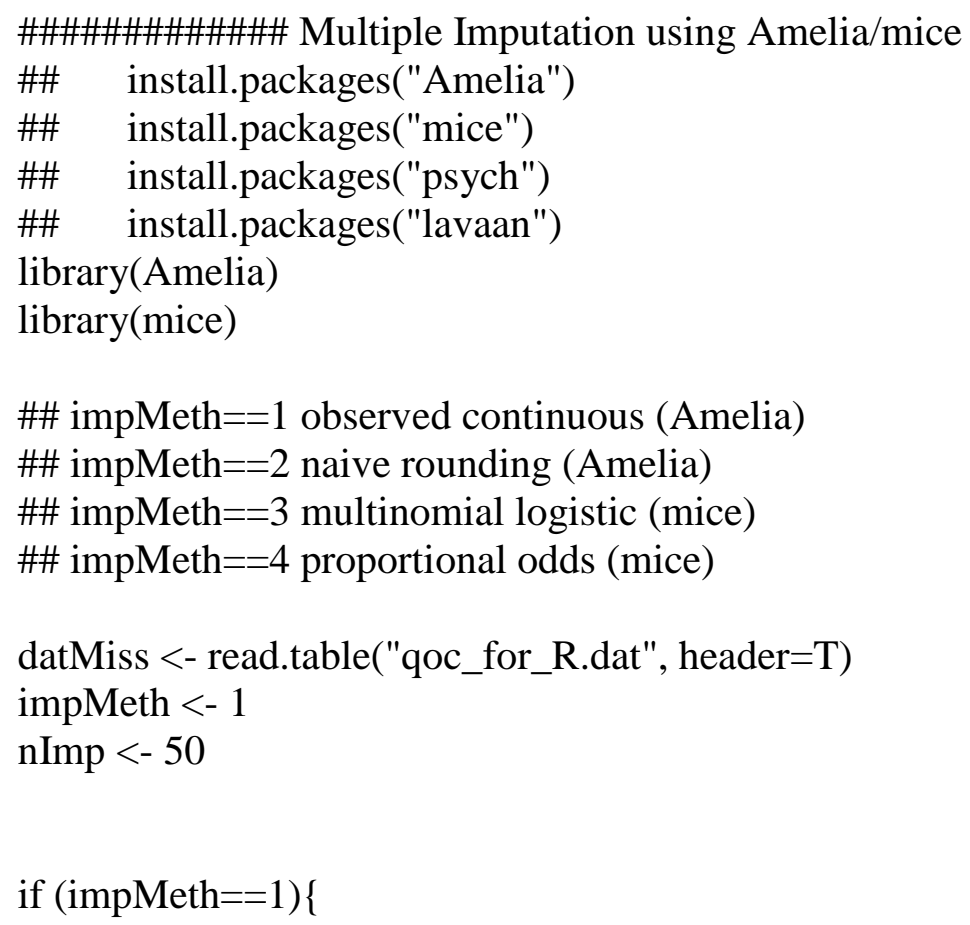




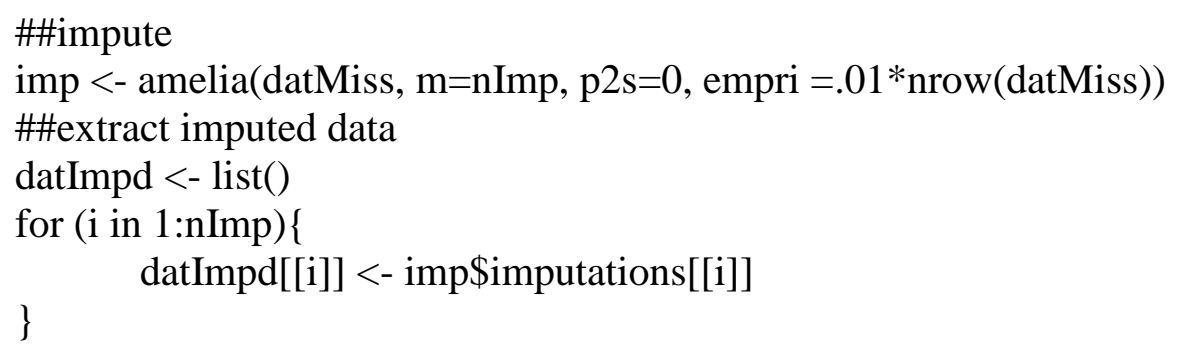




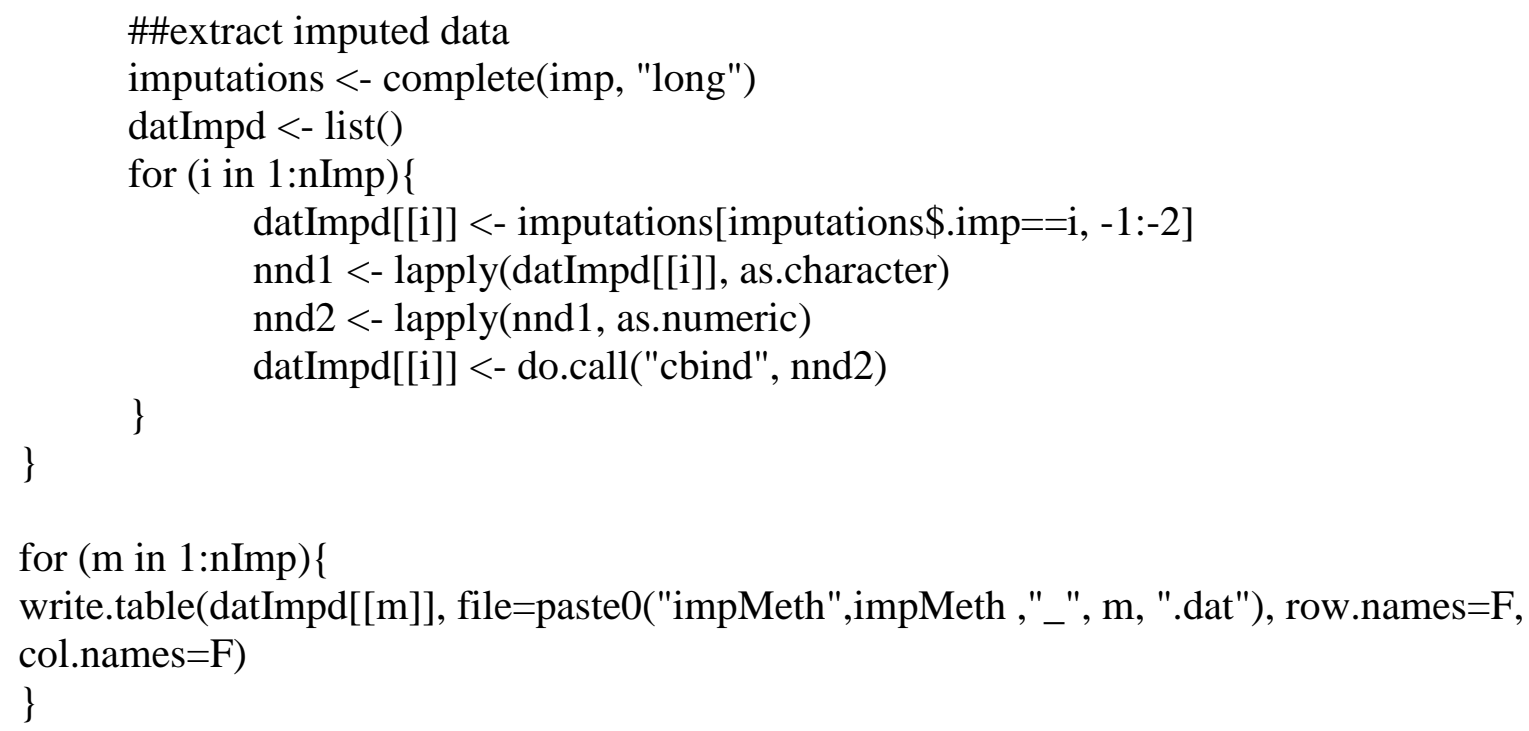

Appendix B

Mplus code for the latent variable approach for the empirical example.

TITLE: multiple imputation

DATA: FILE IS qoc_for_mplus.dat;

VARIABLE: NAMES = gender $\mathrm{a} 1-\mathrm{a} 8 \mathrm{~b} 1-\mathrm{b} 11$;

USEVARIABLES = gender $\mathrm{a} 1-\mathrm{a} 8 \mathrm{~b} 1-\mathrm{b} 11$;

MISSING = ALL (-999);

\section{DATA IMPUTATION:}

IMPUTE = gender (c) a1-a8 (c) b1-b11 (c);

NDATASETS = 50;

SAVE = impMethMplus_*.dat;

ANALYSIS: TYPE = BASIC; 